\title{
Systematic review and perspective on the progress of algal biofuels
}

\author{
Muxin $\mathrm{Hu}^{1, \dagger}$, Dichen $\mathrm{Zhao}^{2, \dagger}$, Qiuchi $\mathrm{Jin}^{3, \dagger}$ and Hanrui $\mathrm{Li}^{4, \dagger}$, Wenmin Wang ${ }^{5, *}$ \\ ${ }^{1}$ Reading Academy, Nanjing University of Information Science \& Technology, Nanjing 210095, China \\ ${ }^{2}$ Reading Academy, Nanjing University of Information Science \& Technology, Nanjing 210095, China \\ ${ }^{3}$ College of Resources and Environmental Sciences, Nanjing Agricultural University, Nanjing 210095, China \\ ${ }^{4}$ College of Environment and Life Sciences, Beijing University of Technology, Beijing 100124, Chin \\ ${ }^{5}$ Shenzhen International Graduate School, Tsinghua University, Shenzhen 518055, PR China. \\ $†$ These authors contributed equally.
}

\begin{abstract}
In recognition of the increasing demand of energy and the worsening environmental problems linked with fossil fuels usage, algal biofuel has been proposed as one of the alternative energy sources. It has become one of the hottest topics in renewable energy field in the new century, especially over the past decade. In this review, we summarized the characteristics of different types of algae biofuels. Besides, an in-depth evaluation of the systematic cultivation and practical application of algae have been conducted. Although algal biofuel has a great potential, its unacceptably high cost limits the large-scale industrialization. In order to resolve such restrictions, feasible methods of improving the large scale production and practical application of algal biofuels are proposed. Future efforts should be focused not only on the cost reduction and innovation techniques, but also towards high value by-products to maximize economic benefits. Our results are dedicated to provide valuable references for subsequent research and guidelines on algae biofuels field.
\end{abstract}

\section{Introduction}

Contemporarily, Human society relies heavily on energy, especially fossil fuels. To be more specific, the demand for fossil fuels is expected to increase by $40 \%$ from 2010 to 2040, where the current reserves are insufficient to meet the demand [1]. In addition, the massive consumption of energy is one of the causes of global warming. The world's carbon dioxide $\left(\mathrm{CO}_{2}\right)$ emissions have reached 36.6 billion ton in 2018 and energy usage is responsible for $87 \%$ of global greenhouse gas emissions [2,3]. These effects have lent urgency for the scientists to search for clean, renewable and affordable energy alternatives [4-7].

Biofuel, defined as the fuel manufactured from a wide range of planted organic sources (comprehensively depicted as biomass), offers an alternative path to gain energy. It has a higher overall cost-benefit and meets the sustainable demand [8-10]. Furthermore, it is cleaner with less harmful carbon emission compared to fossil fuel. Typically, the first biofuel generation uses specific food plants as feedstocks [11]. Second generation biofuels rely on non-food plants and non-edible parts of current crops [12-15]. The algal biofuel, considered as the third generation, has significant advantages [16]. In detail, algae has a great growth rate and can be produced on largescale independent upon agricultural land due to their strong adaptability. Moreover, they are photosynthetic organisms with a high efficiency of absorbing carbon dioxide $\left(\mathrm{CO}_{2}\right)$. In addition, the metabolic engineering of microalgal genome (the fourth-generation algal biofuel) is currently the hottest frontier research [17-20].

On account of the high potential of algae as the alternative feedstock, this review will evaluate several types of algae as feedstocks for production based on primary biological studies. Besides, different cultivation systems will be also introduced with discussion of the application. These results provide reference for the bioenergy field and contribute to the emergent energy problems for the whole human society.

\section{Introduction to algal biofuel mechanisms and species}

\subsection{Introduction to algal biofuel mechanisms}

Microalgae are an ancient group of eukaryotic organisms that constitute a range of species, which are known for their phototrophic nature. However, microalgae strains exhibit a high amount of variation. The oil production capacity of microalgae is much higher than oil-producing plants, e.g., 10 times higher than that of oil seed crops [21]. The most important aspect of microalgae strain selection

*Corresponding author: wangwm17@mails.jlu.edu.cn (Wenmin Wang) 
is the lipids production ability. Biomass productivity, lipid content, and lipid productivity are the three considering parameters when comparing microalgae in terms of lipid production. Many microalgae strains can be used in biofuel production including phytoplankton, red microalgae, green microalgae, and cyanobacteria.

Biodiesel is usually composed of fatty acid methyl ester (FAME) and sometimes fatty acid ethyl ester (FAEE) molecules, which have a molar mass of about $290 \mathrm{~g} / \mathrm{mol}$. The lipid precursors of these molecules are stored in liposomes of the cytoplasm. Liposomes are round organelles that not only store lipids, but are also responsible for lipid transport, protein storage and degradation, etc. The strains with high lipid production are favorable under the goal of biodiesel production. Whereas, strains with high starch concentration are idea if the desired product is ethanol. Starch, the main source of energy for microalgae, is produced based on chloroplasts photosynthesis. Triacylglycerols (TAG) and other fatty acid derivatives act as a secondary energy source located in the cytoplasm of microalgae. These biomolecules serve as both electron sinks and energy reserves for microalgal metabolism. The figure 1 schematicl shows the procedure of chloroplast photosystem. The light enters the cell absorbed by the chloroplast, triggering the oxidationreduction reaction. Subsequently, high-energy electrons are produced, which are then shuttled by NADPH into the Calvin cycle. The products of this cycle are used to make precursors for various molecules, including starch and TAG. TAG can be synthesized in the chloroplast and endoplasmic reticulum [22].

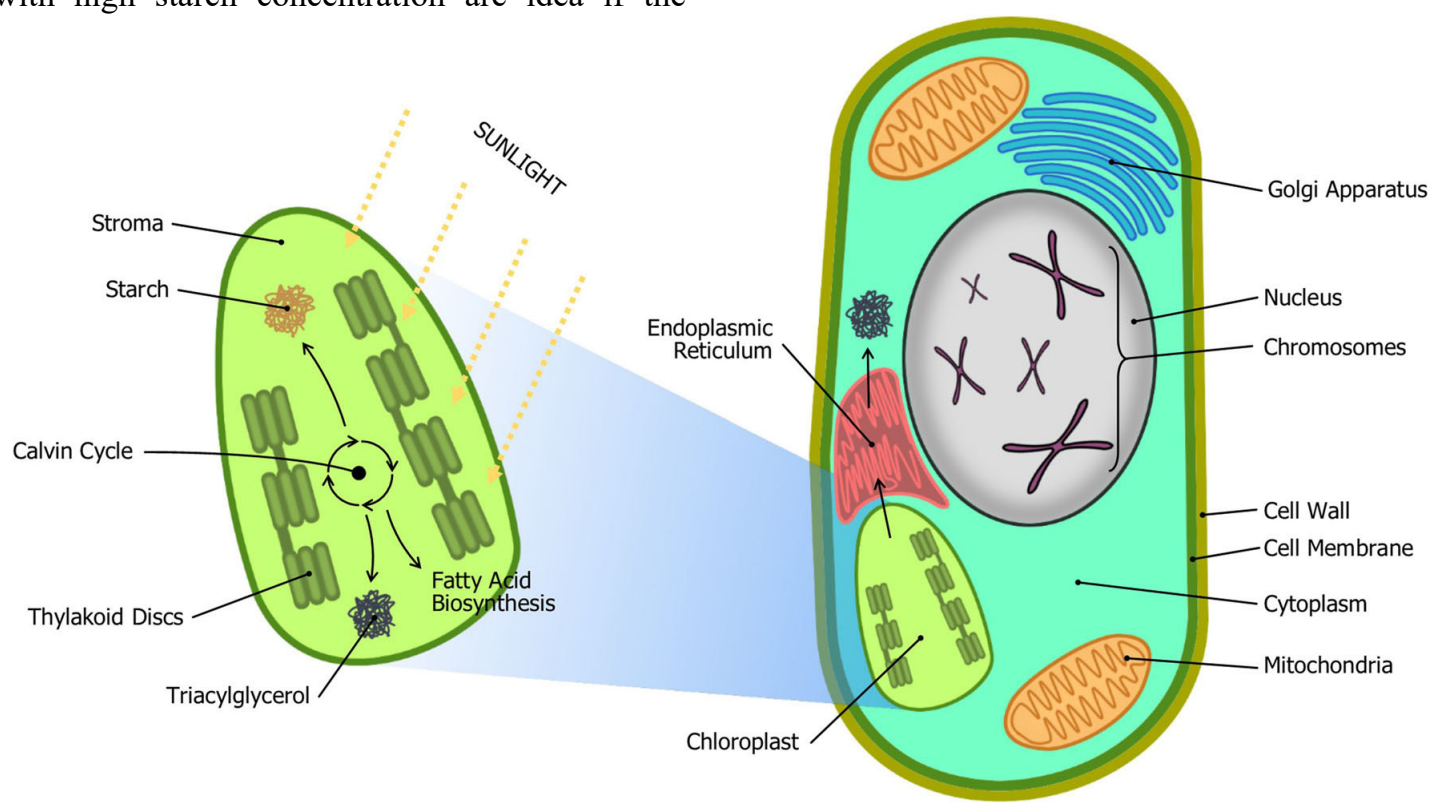

Figure 1. A schematic of energy reservation in microalgae[22]

\subsection{Introduction to algal biofuel species}

Studies on algal breeding have been carried out throughout the past 10 years [24]. Chlorella is the best studied species of algal, while the number of studies on Chlamydomonas, Nannochloropsis, Scenedesmus, and Spirulina have risen rapidly. The microalgae reported for biodiesel production were Chlorella, Scenedesmus, and Botryococcus braunii, which possess oil levels between $20 \%$ and $50 \%$ with favorable productivities. Thereinto, Chlorella appears to be the best option for biodiesel production. Chlorella is a spherical unicellular alga with a diameter of $3-8 \mu \mathrm{m}$ belonging to Chlorophyta, Chlorophyceae, Chlorellaceae. In addition to Chlorella, other algae have rich applications in the biofuel field. The Table 1 lists the lipid productivity of 12 algae species, several of the more common ones for which we give detailed descriptions later. As shown in the table, the highest lipid productivity was found in Chlorella (204.91 mg 1-1 day1) and Botryococcus strains (112.43 and 98.00 mg 1-1 day -1 for Botryococcus braunii and Botryococcus terribilis, respectively).

Chlamydomonas Reinhardtii is a eukaryotic unicellular organism with a large cup-shaped chloroplast, accounting for $40 \%-60 \%$ of the cell volume, surrounding the nucleus. Two flagella located at the top of the cell and photoreceptor eye spots located on the side of the cell. Rhinophytes are characterized by simple culture conditions, short growth cycle, high photosynthetic efficiency, and clear genetic background. Scenedesmus obliquus is a green alga. In recent years, it has been a commonly used test organism due to its relatively high oil production, sensitivity to toxins, easy availability, small size, rapid reproduction, and ability to evaluate the effects of chemicals on multiple generations immediately. Spirulina is a unicellular aquatic plant. The cell walls are very thin and soft composed of easily digestible polysaccharides instead of indigestible toxic substances such as tannins. Spirulina cells do not have a true nucleus, i.e., they are also called cyanobacteria. Ankistrodesmus falcatus is a single-cell green alga with extremely tough cell walls. Therefore, the tough cell wall is a barrier when extracting lipids. Botryococcus braunii is a widespread microalga located in temperate and tropical freshwaters all 
over the world. This single-celled alga has the potential to produce large amounts of liquid hydrocarbons.

Table 1. Growth kinetics, lipid content, and lipid productivity of different microalgae strains [23].

\begin{tabular}{|c|c|c|c|c|}
\hline Local strains & $\begin{array}{l}\text { Specific growth rate } \\
\mu_{0} \ln \left(N_{\mathrm{y}} / N_{\mathrm{x}}\right) /\left(t_{\mathrm{y}}-t_{\mathrm{x}}\right)\left(\mathrm{day}^{-1}\right)\end{array}$ & $\begin{array}{l}\text { Biomass productivity } \\
P_{\mathrm{dwt}}\left(\mathrm{g}^{-1} \mathrm{day}^{-1}\right)\end{array}$ & $\begin{array}{l}\text { Lipid content } \\
\left(L_{\mathrm{c}} ; \% \mathrm{dwt}\right)\end{array}$ & $\begin{array}{l}\text { Volumetric lipid } \\
\text { productivity } \\
\begin{array}{l}P_{\mathrm{dwt}} \times L_{\mathrm{c}} \times 10^{3} \quad\left(\mathrm{mg} \quad 1^{-1}\right. \\
\left.\mathrm{day}^{-1}\right)\end{array} \\
\end{array}$ \\
\hline $\begin{array}{l}\text { Ankistrodesmus } \\
\text { falcatus }\end{array}$ & 0.57 & 0.34 & $16.49 \pm 0.44$ & $56.07 \pm 1.75$ \\
\hline $\begin{array}{l}\text { Ankistrodesmus } \\
\text { fusiformis }\end{array}$ & 0.39 & 0.24 & $20.66 \pm 2.07$ & $49.58 \pm 5.74$ \\
\hline $\begin{array}{l}\text { Kirchneriella } \\
\text { lunaris }\end{array}$ & 0.25 & 0.14 & $17.30 \pm 1.12$ & $24.22 \pm 1.81$ \\
\hline $\begin{array}{l}\text { Chlamydomona } \\
S \text { sp. }\end{array}$ & 0.30 & 0.24 & $15.07 \pm 0.95$ & $36.17 \pm 2.61$ \\
\hline $\begin{array}{l}\text { Chlamydocapsa } \\
\text { bacillus }\end{array}$ & 0.75 & 0.32 & $13.52 \pm 0.65$ & $43.26 \pm 2.40$ \\
\hline $\begin{array}{l}\text { Coelastrum } \\
\text { microporum }\end{array}$ & 0.13 & 0.11 & $20.55 \pm 0.99$ & $22.61 \pm 1.26$ \\
\hline $\begin{array}{l}\text { Desmodesmus } \\
\text { brasiliensis }\end{array}$ & 0.28 & 0.13 & $17.99 \pm 0.42$ & $23.39 \pm 0.63$ \\
\hline $\begin{array}{l}\text { Scenedesmus } \\
\text { obliquus }\end{array}$ & 0.21 & 0.16 & $16.73 \pm 1.37$ & $26.77 \pm 2.53$ \\
\hline $\begin{array}{l}\text { Pseudokirchner } \\
\text { iella } \\
\text { subcapitata }\end{array}$ & 0.27 & 0.08 & $28.43 \pm 5.40$ & $22.74 \pm 4.97$ \\
\hline $\begin{array}{l}\text { Chlorella } \\
\text { vulgaris }\end{array}$ & 0.53 & 0.73 & $28.07 \pm 4.31$ & $204.91 \pm 6.37$ \\
\hline $\begin{array}{l}\text { Botryococcus } \\
\text { braunii }\end{array}$ & 0.14 & 0.25 & $44.97 \pm 4.00$ & $112.43 \pm 11.52$ \\
\hline $\begin{array}{l}\text { Botryococcus } \\
\text { terribilis }\end{array}$ & 0.13 & 0.20 & $49.00 \pm 1.48$ & $98.00 \pm 3.42$ \\
\hline
\end{tabular}

\section{Systematic culture of algae}

After selecting suitable algae for bioenergy production, the key step to affect their energy output is large-scale culture. Combined with the physiological needs of algae, algae culture is mainly divided into autotrophic and heterotrophic. The influencing factors include light, nutrition, temperature, $\mathrm{PH}$ and so on [25]. At present, the market adopts autotrophic culture more.

\subsection{Light autotrophic culture}

The key to light autotrophic culture is the criteria for adequate light. With light, carbon dioxide and water, microalgae can synthesize organic matter and produce the energy for growth through photosynthesis, where oxygen is usually a by-product [26]. Autotrophic culture mainly adopts open photobioreactor and closed photobioreactor.

There are two kinds of open bioreactor, horizontal and inclined, which cannot supply energy independently. The horizontal photobioreactor is placed horizontally on the ground to realize the culture medium circulation by stirring the paddle wheel or rotating arm. The inclined photobioreactor is placed on an inclined surface and the culture medium forms turbulence on the surface through the power of the pump [27]. Currently, efficient open photoreactors are horizontal open runway pools (seen from Fig. 2), 98\% of commercial algal biomass is produced runway pools [28]. The open bioreactor is simple in structure and easy to operate. The maintenance and culture costs of building open reaction tanks are relatively low. However, the reactor is easy to be polluted and affected by the environment because of the open culture, resulting in low stability. The parameters of microalgae culture process cannot be accurately monitored, i.e., both the birth efficiency and the added value of its products are low.

Closed bioreactors are mainly divided into column type, tube type and flat type (illustrated in Fig. 3). The most commonly used reactor is tubular reactor[29]. Closed photobioreactors are mainly constructed of transparent materials to allow light energy to pass through as well as facilitate direct external observation and detection of internal reactions. Compared with the open photobioreactor, the main advantage of this closed photobioreactor is the realization of continuous production (at least in certain degree) [27]. Moreover, the growth 
parameters of microalgae are easy to monitor with stable environment owing to closed characteristics. However, the construction and culture cost is higher for the closed case. Furthermore, the culture tank is difficult to clean and to be utilized for large-scale cultivation of microalgae. At present, most of the algae are used to produce high valueadded products [30].

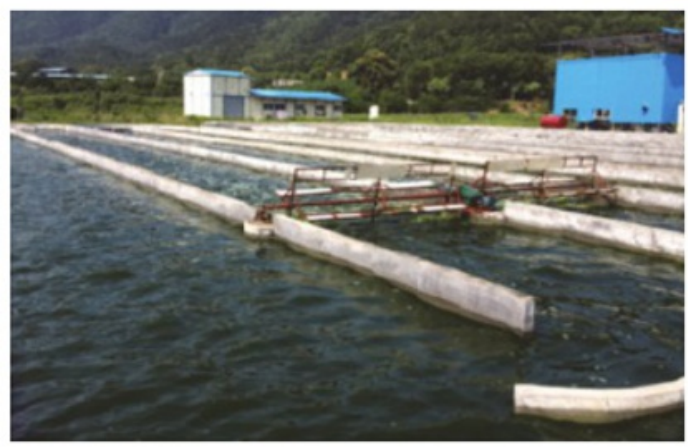

Figure 2. Open bioreactor and open raceway ponds (microalgae cultivation by Guangzhou Institute of Energy Conversion, Chinese Academy of Sciences) [28].

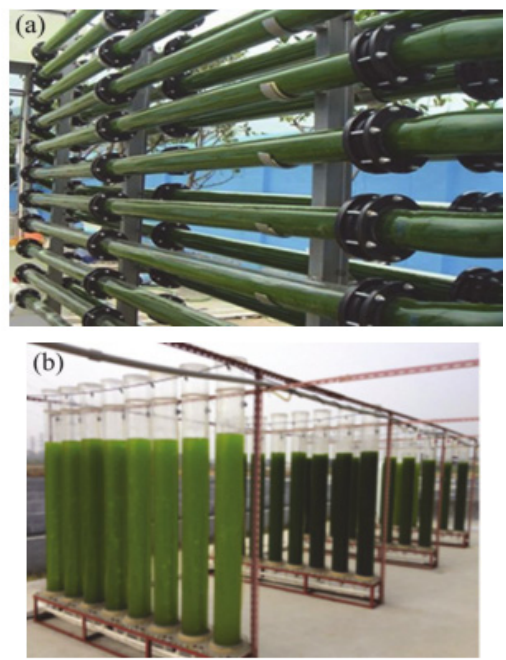

(c)

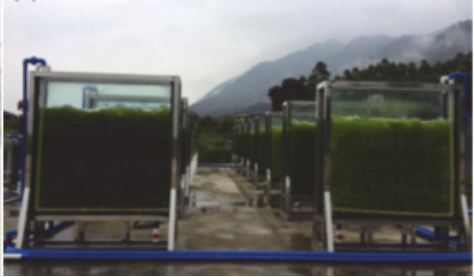

Figure 3. Types of closed bioreactor: (a)tubular photobioreactors; (b)air-lift columnar photobioreactors; (c)plate-type photobioreactors [28].

\subsection{Microalgae heterotrophic culture}

The heterotrophic culture uses organic matter as the source of energy and does not need light. As a consequence, the reaction device is capable of adopting the traditional fermentation device (depicted in Fig. 4). In other words, it does not need the complex culture device with smaller area than the open reaction tank. The growth rate and culture density of microalgae are higher than those under autotrophic conditions. Tetraselmis suecica biomass yield is 2-3 times higher under completely dark heterotrophic culture than under autotrophic conditions[31]. Many microalgae have higher oil productivity under heterotrophic conditions, their lipid content can reach up to $80 \%$ of dry weight. Microalgae heterotrophic culture is not restricted by environmental factors with a low cost. Nevertheless, heterotrophic culture requires a large amount of oxygen. In addition, oxygen supply is an important factor that limits the scale culture of microalgae $[32,33]$.

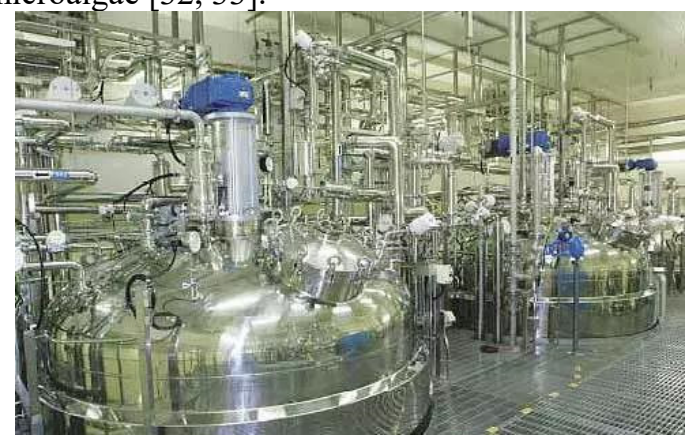

Figure 4. Devices of microalgae heterotrophic culture. (http://www.qibebt.ac.cn/)

\subsection{Wastewater culture microalgae}

The existing culture tank requires to invest a lot of nutrients and energy consumption. Although the new photobioreactor is being developed, the culture cost of microalgae is still very high. In order to reduce the culture cost of microalgae, it has become a hot topic to cultivate microalgae by sewage and treat the sewage simultaneously. In most domestic and agricultural wastewater, there are different concentrations of organic matter, nitrogen and phosphorus can be removed from sewage and obtained by microalgae biomass at the same time [34, 35]. Recently, the Guangzhou Energy Research Institute of the Chinese Academy of Sciences has established a research site in Foshan City, Guangdong Province, to use dairy wastewater to cultivate microalgae and treat sewage by microalgae biomass [28]. In the future, the technology of using sewage to cultivate microalgae and obtain bioenergy will become more and more mature to realize sustainable development.

\section{Algal biofuel products}

As the third generation biofuel feedstock, algae can grow nearly in all kinds of water and can be mainly used to produce biodiesel, bioethanol, biohydrogen and biomethane [36].

\subsection{Bioethanol}

Bioethanol is ethanol originated from a biological source. It is a renewable energy and able to be an alternative to gasoline. Compared to fossil fuels, bioethanol emits much less greenhouse gas when it burns, which is also widely utilized in industries [36].

Both macroalgae and microalgae can be used to produce bioethanol, as they have the ability to store carbohydrates. After harvested, algae biomass is converted 
to carbohydrates by physical methods or enzymatic hydrolysis of cell walls. The next step is fermentation, where separate hydrolysis and fermentation (SHF) as well as simultaneous saccharification and fermentation (SSF) are the most common methods [37-39]. The products of fermentation are finally distilled to remove impurities and ensure the concentration of ethanol. Moreover, microalgae can produce ethanol directly in dark and anaerobic conditions [40-42]. Algenol has developed the technology to produce ethanol directly from the photosynthate of cyanobacteria. In addition, cyanobacteria is capable of converting the carbon fixed by photosynthesis to ethanol by introducing new genes [43]. In macroalgae, some kinds of green and red seaweeds have good ethanol yields [44]. Specifically, U. pertusa is able to produce $0.48 \mathrm{~g}$ ethanol $/ \mathrm{g}$ algae with the fermentation of Saccharomyces cerevisiae ATCC24858 [45]. The ethanol yield of red seaweeds is relatively lower than green ones, but there are still efficient species. Ethanol yield of $\mathrm{G}$. verrucosa will be $0.48 \mathrm{~g}$ ethanol $/ \mathrm{g}$ algae [46]. As for microalgae, there are few kinds which have lower ethanol yield than macroalgae. Chlorococum sp. produces $3.83 \mathrm{~g}$ of ethanol from $10 \mathrm{~g}$ of lipid-extracted microalgae debris [47] while the number for Chlorella vulgaris is $0.4 \mathrm{~g}$ ethanol/g algae [48].

\subsection{Biodiesel}

Biodiesel from algae is environmentally-friendly since it has less emission of greenhouse gases (e.g., $\mathrm{CO} 2$ and NOX), i.e., it is a good alternative to fossil fuels [36].

Both microalgae and macroalgae can be used to produce biodiesel. After dewatering the harvested algae, cell walls of algae need to be ruptured to release lipid. To rupture the cells, microwave, ultrasonic, autoclaving, freezing and organic solvent are all common methods. Thereinto, microwave and ultrasonic method are relatively efficient to extract algal oil [49, 50]. Transesterification is the traditional method to produce biodiesel. According to the types of catalyst, the production methods can be divided into four categories, acid catalysis, alkali catalysis, enzyme catalysis and supercritical methanol method [51]. Alkali catalysis is usually applied for industrial production with attributions of non-pollution and recyclable. With regard to other methods, they usually require strict reaction conditions or cost a lot, i.e., difficult for them to be introduced to practical production. Although the algae have been researched, there are few that have considerable yields. For example, biodiesel yield of Spirulina sp. can reach $86 \%$ by in situ process [52]. Another potential type of algae is Chlorella pyrenoidosa which yields $95 \%$ by in principal [53].

\subsection{Biohydrogen}

Biohydrogen is a renewable and non-polluting method. It is also an important industrial gas which can be widely applied in metal, chemical, electronic and many other industries [54].

In algal biomass, biohydrogen is mainly produced by fermentation and photosynthesis. According to the light conditions, the fermentation process can be divided into photofermentation and dark fermentation. There is little hydrogen produced in dark fermentation. Photosynthesis also occurs in two mechanisms, the direct photolysis and indirect photolysis [55]. There are some kinds of microalgae to produce hydrogen by dark fermentation that have shown potential yields. Most studies tend to take advantage of the combined thermal-chemical process, as this technique is easy to operate and less fermentation inhibitors would be generated [56]. The hydrogen production of Chlorella vulgaris can reach $190.90 \mathrm{~mL}$ $\mathrm{H} 2 / \mathrm{g}$ volatile solid(VS) [57]. Spirogyra sp. can produce $146.3 \mathrm{~mL} \mathrm{H} 2 / \mathrm{g}$ algae [58]. In addition to produce hydrogen from one species of algae, it seems that mixing several kinds of algae may have a better hydrogen yield. The production yield of Chlorella pyrenoidosa powder and rice residue pulp in the ratio of 5:1 will reach $201.8 \mathrm{~mL}$ $\mathrm{H} 2 / \mathrm{g}$ VS [59].

\subsection{Biomethane}

Biomethane is a renewable energy that can be used for heating and transportation [60]. All kinds of microalgal biomass have great potential in producing methane. The main reaction mechanism is anaerobic digestion, which can be divided into four stages Hydrolysis, acidogenesis, acetogenesis, methanogenesis. The effluent of the anaerobic digestion system, which is rich in nutrients, can function as the fertilizer for microalgae while reuse for itself in the mean time [61]. However, there is a more potential technique to produce biomethane and biohydrogen at the same time. It is the two-stage anaerobic fermentation (TSAF), which is a combination of first-stage biohydrogen fermentation and second-stage biomethane fermentation. This technique is of great efficiency for algae to produce gaseous biofuels [62]. For example, Sargassum sp. is able to produce $541 \mathrm{~mL} \mathrm{CH} 4 / \mathrm{g}$ VS as well as $91 \mathrm{~mL} \mathrm{H} / \mathrm{g}$ VS [63] and $434.38 \mathrm{~mL} \mathrm{CH} 4 / \mathrm{g}$ VS and $5.15 \mathrm{~mL} \mathrm{H} 2 / \mathrm{g}$ VS by the treatment at $150{ }^{\circ} \mathrm{C}$ for Chlorella sp. [62]. With regard to Laminaria japonica, its biohydrogen production will reach $87.8 \mathrm{H} 2 / \mathrm{g}$ VS and biomethane production can reach $463.5 \mathrm{CH} 4 / \mathrm{g}$ VS [64].

\section{Suggestions}

The existing technology of algae energy development and production is relatively mature, but the high cost still limits its development. Thus, the cost of biofuel production must be further reduced and the production must be scaled up. New approaches should be proposed to improve the production process, in order to increase the output of fuel energy (e.g., biodiesel) and generate higher economic benefits.

A promising strategy in algal breeding is the application of techniques developed in metabolic engineering and synthetic biology. However, this approach requires an oil gel algae model with high oil production capacity, known genetic information, and established molecular manipulation methods. Therefore, in order to find out the most suitable algae specie, one is ought to 
explore the molecular information of algae and use genetic engineering technology to operate at the molecular level. So far, the fourth generation of biofuels aims to improve the production of algae biofuels via genetic engineering [65]. For biological hydrogen production, for the sake of improving the activity and yield of hydrogenase, algae strains need to withstand high concentration of oxygen and high efficiency of hydrogen production [66]. Therefore, more efficient algae varieties can be cultivated by mutagenesis breeding and genetic modification techniques. Nevertheless, genetic engineering may also pose a potential threat to natural ecosystems, i.e., it is crucial to monitor possible risks in a timely manner.

For large-scale culture, new techniques are proposed to improve the efficiency of the culture pool (e.g.., the recent algal adherent culture technology, which reduces the culture cost and increases the production of biomass $[67,68])$. On the other hand, the cultivation of algae through sewage to form a large-scale is still hot research. This can not only replace the factories to treat sewage alone, but also reduce the size of algae culture by using different nutrient elements in sewage. Whereas, the stateof-art technology is still not mature enough. In the future, the investigation should be carried out to select algae species with higher yield and value by-products in different sewage (livestock sewage, domestic sewage, industrial sewage, etc.).

\section{Conclusions}

In summary, biofuel have attracted a great deal of interest due to its renewable, biodegradable and environmentalfriendly nature. Algae are attractive feedstock for biofuel production with advantages of great growth rate, strong environmental adaptability and high lipid content. In this review, the cultivation and biofuel applications are compared and discussed for several types of algae. We find that sustainable and large-scale usage of algae biofuels is far from enough, where high cost remains the key challenge. In order to industrialize algae biofuels desirably, more research on innovation and efficiency is needed in the future. Further research orientation could focus on mutagenesis breeding and genetic modification techniques for algae cultivation. Moreover, to maximize the total benefits both economically and socially, research about algal biofuel by-products is also demanded.

\section{References}

1. Saad MG, Dosoky NS, Zoromba MS, Shafik HM. Algal Biofuels: Current Status and Key Challenges. Energies 2019;12.

2. Gilfillan D, Marland G, Boden T, Andres R. Global, Regional, and National Fossil-Fuel CO2 Emissions. Appalachian Energy Center; 2019.

3. Project GC. Supplemental data of Global Carbon Budget 2020 (Version 1.0) [Data set]. . Global Carbon Project; 2020.
4. Li M, Luo N, Lu Y. Biomass Energy Technological Paradigm (BETP): Trends in This Sector. Sustainability 2017;9.

5. Raheem A, Prinsen P, Vuppaladadiyam AK, Zhao M, Luque R. A review on sustainable microalgae based biofuel and bioenergy production: Recent developments. Journal of Cleaner Production 2018; 181:42-59.

6. Goncalves EC, Wilkie AC, Kirst M, Rathinasabapathi B. Metabolic regulation of triacylglycerol accumulation in the green algae: identification of potential targets for engineering to improve oil yield. Plant Biotechnology Journal 2016;14:1649-60.

7. Ho DP, Huu Hao N, Guo W. A mini review on renewable sources for biofuel. Bioresource Technology 2014;169:742-9.

8. Xue S-J, Chi Z, Zhang Y, Li Y-F, Liu G-L, Jiang H, et al. Fatty acids from oleaginous yeasts and yeast-like fungi and their potential applications. Critical Reviews in Biotechnology 2018;38:1049-60.

9. Polburee P, Yongmanitchai W, Lertwattanasakul N, Ohashi T, Fujiyama K, Limtong S. Characterization of oleaginous yeasts accumulating high levels of lipid when cultivated in glycerol and their potential for lipid production from biodiesel-derived crude glycerol. Fungal Biology 2015;119:1194-204.

10. Agarwal A, Rana M, Park J-H. Advancement in technologies for the depolymerization of lignin. Fuel Processing Technology 2018;181:115-31.

11. Areal FJ, Riesgo L, Rodriguez-Cerezo E. Economic and agronomic impact of commercialized GM crops: a meta-analysis. Journal of Agricultural Science 2013;151:7-33.

12. Brown TR, Brown RC. A review of cellulosic biofuel commercial-scale projects in the United States. Biofuels Bioproducts \& Biorefining-Biofpr 2013;7:235-45.

13. Andree BPJ, Diogo V, Koomen E. Efficiency of second-generation biofuel crop subsidy schemes: Spatial heterogeneity and policy design. Renewable \& Sustainable Energy Reviews 2017;67:848-62.

14. Aguilar DL, Rodriguez-Jasso RM, Zanuso E, de Rodriguez DJ, Amaya-Delgado L, Sanchez A, et al. Scale-up and evaluation of hydrothermal pretreatment in isothermal and non-isothermal regimen for bioethanol production using agave bagasse. Bioresource Technology 2018;263:112-9.

15. Stefan 1, Sammy B. Advances in the Production of High-Value Products by Microalgae. Industrial Biotechnology 2014;10.

16. Nigam G, Singh R, Chaturvedi AK. Finite Duration Root Nyquist Pulses with Maximum In-Band Fractional Energy. Ieee Communications Letters 2010;14:797-9.

17. Lue J, Sheahan C, Fu P. Metabolic engineering of algae for fourth generation biofuels production. Energy \& Environmental Science 2011;4:2451-66. 
18. Dutta K, Daverey A, Lin J-G. Evolution retrospective for alternative fuels: First to fourth generation. Renewable Energy 2014;69:114-22.

19. Adeniyi OM, Azimov U, Burluka A. Algae biofuel: Current status and future applications. Renewable \& Sustainable Energy Reviews 2018;90:316-35.

20. Sharma S, Basu S, Shetti NP, Aminabhavi TM. Waste-to-energy nexus for circular economy and environmental protection: Recent trends in hydrogen energy. Science of the Total Environment 2020;713.

21. Gao C, Wang Y, Shen Y, Yan D, He X, Dai J, et al. Oil accumulation mechanisms of the oleaginous microalga Chlorella protothecoides revealed through its genome, transcriptomes, and proteomes. Bmc Genomics 2014;15.

22. Dickinson S, Mientus M, Frey D, Amini-Hajibashi A, Ozturk S, Shaikh F, et al. A review of biodiesel production from microalgae. Clean Technologies and Environmental Policy 2017;19:637-68.

23. Chen H, Li TP, Wang Q. Ten years of algal biofuel and bioproducts: gains and pains. Planta 2019;249:195-219.

24. Nascimento IA, Marques SSI, Cabanelas ITD, Pereira SA, Druzian JI, de Souza CO, et al. Screening Microalgae Strains for Biodiesel Production: Lipid Productivity and Estimation of Fuel Quality Based on Fatty Acids Profiles as Selective Criteria. Bioenergy Research 2013;6:1-13.

25. Zhu J Y RJF, Zong B N. Factors in mass cultivation of microalgae for biodiesel[J]. Chinese journal of catalysis $2013 ; 34: 21$.

26. UKEssays. Growth Of Microalgae Using Led Lighting Biology Essay. 2018.

27. Yong F ZG xLR-nL. Energy Microbiology. 2013.

28. Zhu SN LF, Fan JH. Research Progress and Prospect of Microalgae Bioenergy. Advances in New and Renewable Energy 2018;6:8.

29. Photobioreactors: production systems for phototrophic microorganisms[J]. Applied microbiology and biotechnology 2001;57:7.

30. Fan XL GR-b, Wei DZ. Energy Microalgae and Biorefinery. China Basic Science 2009;5:5.

31. Azma M MM, Mohamed R, et al. Improvement of medium composition for heterotrophic cultivation of green microalgae, Tetraselmis suecica, using response surface methodology. Biochem Een J 2011;53:9.

32. Clark G J LD, Bushell M E. Oxygen Limitation can induce microbial secondary metabolite formation: investigations with miniature electrodes in shaker and bioreactor culture Microbiology. 1995;141:7.

33. Wu Z Y SXM. Optimization for high-density cultivation of heterotrophic Chlorella based on a hybrid neural network mode[J]. Letters in applied microbiology 2007;44:6.

34. Qin L WZM, Sun Y M, et al. Microalgae consortia cultivation in daily wastewater to improve the potential of nutrient removal and biodiesel feedstock production[J]. Environmental science and pollution research 2016;23:9.

35. Zhu L D TJ, Hiltunen E, et al. Recycling harvest water to cultivate Chlorella zofingiensis under nutrient limitation for biodiesel production[J]. Bioresource technology 2013:7.

36. Anto S, Mukherjee SS, Muthappa R, Mathimani T, Deviram G, Kumar SS, et al. Algae as green energy reserve: Technological outlook on biofuel production. Chemosphere 2020;242:125079.

37. Rubin EM. Genomics of cellulosic biofuels. Nature 2008;454.

38. Matsumoto M, Yokouchi H, Suzuki N, Ohata H, Matsunaga T. Saccharification of marine microalgae using marine bacteria for ethanol production. Applied Biochemistry and Biotechnology 2003;105.

39. Ojeda K, Sánchez E, El-Halwagi M, Kafarov V. Exergy analysis and process integration of bioethanol production from acid pre-treated biomass: Comparison of SHF, SSF and SSCF pathways. Chemical Engineering Journal 2011;176-177:195201.

40. Hirayama S, Ueda R, Ogushi Y, Hirano A, Samejima $\mathrm{Y}$, Hon-Nami K, et al. Ethanol production from carbon dioxide by fermentative microalgae. Studies in Surface Science and Catalysis 1998;114.

41. Hirano A, Ueda R, Hirayama S, Ogushi Y. CO 2 fixation and ethanol production with microalgal photosynthesis and intracellular anaerobic fermentation. Energy 1997;22.

42. Ueda R, Hirayama S, Sugata K, Nakayama H. Process for the production of ethanol from microalgae. Mitsubishi Jukogyo Kabushiki Kaisha; 1996. p. 2848-.

43. Deng MD, Coleman JR. Ethanol synthesis by genetic engineering in cyanobacteria. Applied and environmental microbiology 1999;65.

44. Ramachandra TV, Hebbale D. Bioethanol from macroalgae: Prospects and challenges. Renewable and Sustainable Energy Reviews 2020;117:109479.

45. Choi WY, Han JG, Lee CG, Song CH, Kim JS, Seo $\mathrm{YC}$, et al. Bioethanol Production from Ulva pertusa Kjellman by High-temperature Liquefaction. Chemical \& Biochemical Engineering Quarterly 2012;26.

46. Nguyen TH, Ra CH, Sunwoo IY, Jeong GT, Kim SK. Bioethanol production from Gracilaria verrucosa using Saccharomyces cerevisiae adapted to $\mathrm{NaCl}$ or galactose. Bioprocess and Biosystems Engineering 2017;40:529-36.

47. Ge L, Wang P, Mou H. Study on saccharification techniques of seaweed wastes for the transformation of ethanol. Renewable Energy 2011;36:84-9.

48. Lee SJ, Oh YH, Kim DH, Kwon DY, Lee CG, Lee JW. Converting carbohydrates extracted from marine algae into ethanol using various ethanolic Escherichia coli strains. Appl Biochem Biotechnol 2011;164:87888 . 
49. Cravotto G, Boffa L, Mantegna S, Perego P, Avogadro M, Cintas P. Improved extraction of vegetable oils under high-intensity ultrasound and/or microwaves. Ultrasonics - Sonochemistry 2008;15.

50. Lee JY, Yoo C, Jun SY, Ahn CY, Oh HM. Comparison of several methods for effective lipid extraction from microalgae. Bioresource technology 2010;101 Suppl 1.

51. Zeng D, Li R, Yan T, Fang T. Perspectives and advances of microalgal biodiesel production with supercritical fluid technology. Rsc Advances 2014:4:39771-81.

52. Xu R, Mi Y. Simplifying the Process of Microalgal Biodiesel Production Through In Situ Transesterification Technology. Journal of the American Oil Chemists' Society 2011;88:91-9.

53. Li P, Miao X, Li R, Zhong J. In Situ Biodiesel Production from Fast-Growing and High Oil Content Chlorella pyrenoidosa in Rice Straw Hydrolysate. Journal of Biomedicine and Biotechnology 2011;2011:141207.

54. Ramachandran R, Menon RK. An overview of industrial uses of hydrogen. International Journal of Hydrogen Energy 1998;23:593-8.

55. Sharma A, Arya SK. Hydrogen from algal biomass: A review of production process. Biotechnology Reports 2017;15:63-9.

56. Nagarajan D, Chang J-S, Lee D-J. Pretreatment of microalgal biomass for efficient biohydrogen production - Recent insights and future perspectives. Bioresource Technology 2020;302:122871.

57. Stanislaus MS, Zhang N, Yuan Y, Zheng H, Zhao C, $\mathrm{Hu} \mathrm{X}$, et al. Improvement of biohydrogen production by optimization of pretreatment method and substrate to inoculum ratio from microalgal biomass and digested sludge. Renewable Energy 2018;127:670-7.

58. Pinto T, Gouveia L, Ortigueira J, Saratale GD, Moura P. Enhancement of fermentative hydrogen production from Spirogyra $\mathrm{sp}$. by increased carbohydrate accumulation and selection of the biomass pretreatment under a biorefinery model. Journal of Bioscience and Bioengineering 2018;126:226-34.

59. Sun C, Xia A, Liao Q, Fu Q, Huang Y, Zhu X, et al. Improving production of volatile fatty acids and hydrogen from microalgae and rice residue: Effects of physicochemical characteristics and mix ratios. Applied Energy 2018;230:1082-92.

60. Wall DM, McDonagh S, Murphy JD. Cascading biomethane energy systems for sustainable green gas production in a circular economy. Bioresource Technology 2017;243:1207-15.

61. Ma J, Li L, Zhao Q, Yu L, Frear C. Biomethane production from whole and extracted algae biomass: long-term performance evaluation and microbial community dynamics. Renewable Energy 2021.

62. Wu H, Li J, Liao Q, Fu Q, Liu Z. Enhanced biohydrogen and biomethane production from Chlorella sp. with hydrothermal treatment. Energy Conversion and Management 2020;205:112373.

63. Costa JC, Oliveira JV, Pereira MA, Alves MM, Abreu AA. Biohythane production from marine macroalgae Sargassum sp. coupling dark fermentation and anaerobic digestion. Bioresource Technology 2015;190:251-6.

64. Shi X, Jung K-W, Kim D-H, Ahn Y-T, Shin H-S. Direct fermentation of Laminaria japonica for biohydrogen production by anaerobic mixed cultures. International Journal of Hydrogen Energy 2011;36:5857-64.

65. Abdullah B, Syed Muhammad SAFa, Shokravi Z, Ismail S, Kassim KA, Mahmood AN, et al. Fourth generation biofuel: A review on risks and mitigation strategies. Renewable and Sustainable Energy Reviews 2019;107:37-50.

66. Sustained Photobiological Hydrogen Gas Production upon Reversible Inactivation of Oxygen Evolution in the Green Alga Chlamydomonas reinhardtii. Plant Physiology 2000;122.

67. Liu T, Wang J, Hu Q, Cheng P, Ji B, Liu J, et al. Attached cultivation technology of microalgae for efficient biomass feedstock production. Bioresource Technology 2013;127:216-22.

68. Shen Y, Zhang H, Xu X, Lin X. Biofilm formation and lipid accumulation of attached culture of Botryococcus braunii. Bioprocess and Biosystems Engineering 2015;38:481-8. 